\title{
ANALISIS HUBUNGAN DISIPLIN KERJA TERHADAP PRODUKTIVITAS KERJA DI BADAN KESATUAN BANGSA DAN POLITIK PROVINSI KALIMANTAN SELATAN
}

\author{
Fika Fibriyanita \\ Progam Studi Ilmu Administrasi Publik, Fakultas Ilmu Sosial dan Ilmu Politik \\ Universitas Islam Kalimantan Muhammad Arsyad Al-Banjari Banjarmasin \\ Email : fikafibriyanita@gmail.com
}

\begin{abstract}
ABSTRAK
Pegawai Negeri sebagai unsur aparatur negara dan abdi masyarakat, mempunyai peran yang amat penting dalam rangka menciptakan masyarakat madani yang taat hukum, berperadaban modern, demokratis, makmur, adil, dan bermoral tinggi yang menyelenggarakan pelayanan secara adil dan merata. Tujuan penelitian ini adalah untuk mengetahui hubungan displin kerja terhadap produktivitas kerja di Badan Kesatuan Bangsa Dan Politik Provinsi Kalimantan Selatan berdasarkan karakterisitik jenis kelamin, usia, tingkat pendidikan dan masa kerja. Metode penelitian menggunakan pendekatan kuantitatif dengan jenis penelitian asosiatif. Data dikumpulkan dengan cara menyebar kuesioner kepada responden. Sampel ditentukan dengan menggunakan teknik NonProbability Sampling dengan jenis Purposive Sampling. Analisa data menggunakan statistik dalam perhitungannya dengan bantuan program IBM SPSS Statistics 21.0 for Windows. Hasil penelitian menunjukan disiplin kerja lebih banyak pada kategori sangat baik yaitu 38,1\%, Kurang baik 31,0\%, baik 16,0\% dan cukup baik 19,0\% dari 42 jumlah pegawai dan produktivitas kerja lebih banyak pada kategori cukup baik yaitu 54,8\%, baik 31,0\%, dan kurang baik 9,5\% dari 42 jumlah pegawai. Dapat disimpulkan bahwa koefisien korelasi antara variabel disiplin pegawai $(x)$ dengan kinerja pegawai $(y)$ adalah sebesar $(r)=0,747$ dengan signifikansi 0,000 . Berdasarkan kriteria diatas dapat disimpulkan bahwa korelasi kedua variabel tersebut adalah tidak signifikan, sebab signifikansi yang menyertai lebih kecil dari $0,05(0,000<0,05)$. Dengan demikian korelasi antara variabel disiplin kerja dengan produktivitas kerja yang terjadi bersifat negatif, untuk itu, apabila variabel bebas (independen) menurun, maka akan disertai oleh menurunnya variabel terikat (dependent), korelasi yang terjadi berada dalam kategori rendah.
\end{abstract}

Kata Kunci : Disiplin Kerja, Produktivitas Kerja

\section{ABSTRACT}

Public servants as an element of the state apparatus and public servants have an important role in creating lawabiding, civilized, democratic, prosperous, just and high-moral civil society that provides fair and equitable service. The purpose of this study is to determine the relationship of work discipline to work productivity in Badan Unity Nation And Politics of South Kalimantan Province based on the characteristics of gender, age, education level and years of service. The research method used a quantitative approach with the type of associative research. Data were collected by distributing questionnaires to respondents. The sample was determined using Non-Probability Sampling technique with Purposive Sampling type. Data analysis uses statistics in its calculations with the help of the IBM SPSS Statistics 21.0 for Windows program. The results showed more work discipline in the category of very good that is $38.1 \%$, less good $31.0 \%$, both $16.0 \%$ and quite good $19.0 \%$ of 42 number of employees and work productivity more in the category is good enough 54,8\%, good 31,0\%, and less good 9,5\% from 42 number of employees. It can be concluded that the correlation coefficient between employee discipline variable $(x)$ and employee performance $(y)$ is $(r)=0.747$ with significance 0.000. Based on the above criteria can be concluded that the correlation of both variables is not significant, because the accompanying significance is smaller than $0.05(0.000<0.05)$. Thus the correlation between work discipline variables with work productivity that occurs is negative, therefore, if independent variable (independent) decreases, it will be accompanied by the decrease of dependent variable, correlation that happened is in low category.

Keywords: Work Discipline, Work Productivity

\section{PENDAHULUAN}

\section{Latar Belakang}

Pegawai Negeri sebagai unsur aparatur negara dan abdi masyarakat, mempunyai peran yang amat penting dalam rangka menciptakan masyarakat madani yang taat hukum, berperadaban modern, 
demokratis, makmur, adil, dan bermoral tinggi yang menyelenggarakan pelayanan secara adil dan merata, menjaga persatuan dan kesatuan bangsa dengan penuh kesetiaan kepada Pancasila dan Undang Undang Dasar Tahun 1945

"Seperti halnya dengan perubahan perilaku Aparatur Sipil Negara (ASN) yang diarahkan pada peningkatan disiplin yang berhubungan pada kinerja pegawai yang berkaitan dengan sumber daya manusia". (Harun Arsyad, 2014)

Kemudian, sudah kita ketahui bersama bahwa karyawan atau sumber daya manusia (SDM) memiliki peranan sentral dalam mengembangakan dan mencapai sasaran-sasaran organisasi baik itu organisasi negeri ataupun swasta. "Sasaran-sasaran organisasi tersebut akan mengarahkan pada pencapaian tujuan organisasi sebagai alat untuk meningkatkan efisiensi, efektivitas dan produktivitas kerja organisasi secara keseluruhan". (Sondang P. Siagian, 2015)

Akan tetapi, keberadaan SDM yang hebat dan unggul malah bisa menjadi bumerang bagi organisasi jika tidak di sertai perencanaan dan pengendalian SDM. Untuk itu pengelolaan sumber daya manusia, karena pegawai merupakan aset penting dalam instansi yang mempunyai peran sebagai pemikir, perencanan, dan pengendalian aktivitas, untuk itu faktor pegawai yang diharapkan dapat berprestasi sebaik mungkin demi mencapai tujuan instansi pemerintahan.

Disamping itu sejalan dengan adanya perubahan Peraturan Daerah Provinsi Kalimantan Selatan Nomor 1 Tahun 2012 tentang Pembentukan Organisasi dan Tata Kerja Perangkat Daerah Provinsi Kalimantan Selatan, dan Peraturan Gubernur Kalimantan Selatan Nomor 045 Tahun 2013 Tentang Tugas Pokok, Fungsi dan Uraian Tugas Unsur-unsur Organisasi Badan Kesatuan Bangsa dan Politik Provinsi Kalimantan Selatan. Kantor Badan Kesatuan Bangsa dan Politik Provinsi Kalimantan Selatan dituntut untuk melaksanakan penyusunan dan pelaksanaan kebijakan daerah di bidang kesatuan bangsa dan politik serta mendorong terwujudnya kehidupan politik yang dinamis, demokratis, dan transparan, yang di topang makin mantapnya wawasan, integritas, dan ketahanan bangsa. Agar beroperasi secara lebih efisien dan efektif, fungsi personalia yang terlibat dalam seluruh operasi kantor Badan Kesatuan
Bangsa dan Politik Provinsi Kalimantan Selatan sistem akuntabilitas kinerja dibangun dan dikembangkan dalam rangka perwujudan pertanggungjawaban pelaksanaan tugas dan fungsi serta pengelolaan sumber daya dan pelaksanaan kebijakan dan program yang dipercayakan pada setiap organisasi kerja, berdasarkan suatu sistem akuntabilitas yang memadai.

Sumber daya manusia menjadi aset penting dan berharga, apabila sumber daya tersebut mempunyai kualitas yang tinggi. Sebagai organisasi negeri Badan Kesatuan Bangsa dan Politk Provinsi Kalimantan Selatan tentunya mendukung penuh program pemerintah dengan Peraturan Pemerintah Republik Indonesia Nomor 53 Tahun 2010 Tentang Disiplin Pegawai Negeri Sipil Bab II Kewajiban Dan Larangan Pasal 3 Ayat 9,11, Dan 14 yang berbunyi bahwa, "Pegawai negeri sipil wajib bekerja dengan jujur, tertib, cermat, dan bersemangat untuk kepentingan Negara serata masuk kerja dan mentaati ketentuan jam kerja dan memberikan pelayanan sebaik baiknya kepada masyarakat".

Sebagaimana tujuan awal yang ingin dicapai oleh Kantor Badan Kesatuan Bangsa dan Politik Provinsi kalimantan Selatan adalah salah satu organisasi negeri yang menerapkan penenggakan disiplin kerja kepada setiap pegawainya dan peningkatan kepada pelayanan masyarakat. Adapun pencapaian tujuan ini sangat ditentukan oleh beberapa faktor, termasuk didalamnya adalah sikap disiplin kerja setiap pegawainya, komitmen organisasi untuk mempertahan karyawan, organisasi menerapkan budaya untuk saling pengertian dengan seluruh karyawanya, serta kinerja yang kuat, semua ini bagi organisasi untuk memelihara tenaga kerjanya. Karena itu, pimpinan harus dapat menetapkan sasaran kerja yang akan menghasilkan pegawai yang berkualitas tinggi, bermotivasi tinggi, dan produktif.

Berkaitan dengan pemikiran tersebut di atas, pentingnya penilitian ini dilakukan, dengan mengambil judul analisis disiplin kerja terhadap produktivitas kerja di Badan Kesatuan Bangsa dan Politik Provinsi Kalimantan Selatan.

\section{Disiplin Kerja}

Menurut Rivai dan Sagala (2013:825) disiplin kerja adalah suatu alat yang digunakan para manajer 
untuk berkomunikasi dengan karyawan agar mereka bersedia untuk mengubah suatu perilaku dan untuk meningkatkan kesadaran juga kesediaan seseorang agar menaati semua peraturan dan norma sosial yang berlaku di suatu perusahaan.

Sejalan dengan Rivai dan Sagala, bagi Sintaasih dan Wiratama (2013:129), disiplin kerja adalah merupakan tindakan manajemen untuk mendorong kesadaran dan kesediaan para anggotanya untuk mentaati semua peraturan yang telah ditentukan oleh organisasi atau perusahaan dan norma-norma sosial yang berlaku secara sukarela.

Menurut Setyaningdyah (2013:145) disiplin kerja adalah kebijakan bergeser individu untuk menjadi diri bertanggung jawab untuk mematuhi peraturan lingkungan (organisasi).

Menurut Harlie (2010:117) disiplin kerja pada hakekatnya adalah bagaimana menumbuhkan kesadaran bagi para pekerjanya untuk melakukan tugas yang telah diberikan, dan pembentukan disiplin kerja ini tidak timbul dengan sendirinya.

Seperti Singodimedjo dalam Sutrisno (2012:86), mengatakan bahwa disiplin adalah sikap kesediaan dan kerelaan seseorang untuk memahami dan mentaati norma-norma peraturan yang berlaku disekitarnya.

\section{Produktivitas Kerja}

Menurut Sutrisno (2009:99) produktivitas secara umum diartikan sebagai hubungan antara keluaran (barang-barang atau jasa) dengan masukan (tenaga kerja, bahan, uang).

Tohardi yang dikutip oleh Sutrisno (2011:100) mengungkapkan bahwa produktivitas kerja merupakan sikap mental yang selalu mencari perbaikan terhadap apa yang telah ada, suatu keyakinan bahwa seseorang dapat melakukan pekerjaan lebih baik hari ini daripada hari kemarin, dan hari esok lebih baik dari hari ini.

Pendapat Tohardi didukung juga oleh Ravianto yang dikutip oleh Sutrisno (2011:100) yang menyatakan produktivitas pada dasarnya mencakup sikap mental yang selalu mempunyai pandangan bahwa kehidupan hari ini harus lebih baik dari hari ini. Sikap ini mendorong agar seseorang tidak cepat merasa puas, akan tetapi harus mengembangkan diri dan meningkatkan kemampuan kerja dengan cara selalu mencari perbaikan-perbaikan dan peningkatan.
Menurut Sinungan (2014:17) mengemukakan bahwa Produktivitas adalah suatu konsep yang bersifat universal yang bertujuan untuk menyediakan lebih banyak barang dan jasa yang akan digunakan oleh banyak manusia, dengan menggunakan sumber-sumber riil yang semakin sedikit.

\section{Indikator Disiplin Kerja}

Menurut Hasibuan (2013:194-198), pada dasarnya banyak indikator-indikator yang mempengaruhi tingkat kedisiplinan karyawan suatu organisasi yaitu:

a. Tujuan dan Kemampuan

Tujuan dan kemampuan ikut mempengaruhi tingkat kedisiplinan karyawan. Tujuan yang akan dicapai harus jelas dan ditetapkan secara ideal serta cukup menantang bagi kemampuan karyawan. Hal ini berarti bahwa tujuan (pekerjaan) yang dibebankan kepada karyawan harus sesuai dengan kemampuan karyawan yang bersangkutan, agar dia bekerja sungguh-sungguh dan disiplin dalam mengerjakannya.

b. Teladan Pimpinan

Teladan pimpinan sangat berperan dalam menentukan kedisiplinan karyawan karena pimpinan dijadikan teladan dan panutan oleh para bawahannya. Pimpinan jangan mengharapkan kedisiplinan bawahannya baik jika ia sendiri kurang disiplin. Pimpinan harus menyadari bahwa perilakunya akan dicontoh dan diteladani bawahannya. Hal inilah yang mengharuskan pimpinan mempunyai kedisiplinan yang baik agar para bawahan pun mempunyai disiplin yang baik pula.

c. Balas jasa

Balas jasa (gaji dan kesejahteraan) ikut mempengaruhi kedisiplinan karyawan karena balas jasa akan memberikan kepuasan dan kecintaan karyawan terhadap perusahaan/pekerjaannya. Untuk mewujudkan kedisiplinan karyawan yang baik, perusahaan harus memberikan balas jasa yang relatif besar.

d. Keadilan

Keadilan ikut mendorong terwujudnya kedisiplinan karyawan karena ego dan sifat manusia yang selalu merasa dirinya penting 
dan mita diperlakukan sama dengan manusia lainnya. Keadilan dijadikan dasar kebijaksanaan dalam pemberian balas jasa (pengakuan) atau hukuman akan merangsang terciptanya kedisiplinan karyawan yang baik. Manajer yang cakap dalam memimpin selalu berusaha bersikap adil terhadap semua bawahannya. Dengan keadilan yang baik akan menciptakan kedisiplinan yang baik pula.

e. Waskat

Waskat (pengawasan melekat) adalah tindakan nyata dan paling efektif dalam mewujudkan kedisiplinan karyawan perusahaan. Dengan waskat berarti atasan harus aktif dan langsung mengawasi perilaku, moral, sikap, gairah kerja, dan prestasi kerja bawahannya. Hal ini berarti atasan harus selalu ada/hadir di tempat kerja agar dapat mengawasi dan memberikan petunjuk, jika ada bawahannya yang mengalami kesulitan dalam menyelesaikan pekerjaannya.Dengan waskat, atasan secara langsung dapat mengetahui kemampuan dan kedisiplinan setiap individu bawahannya, sehingga konduite setiap bawahan dinilai objektif. Waskat bukan hanya mengawasi moral kerja dan kedisiplinan karyawan saja, tetap juga harus berusaha mencari sistem kerja yang lebih efektif untuk mewujudkan tujuan organisasi, karyawan, dan masyarakat. Dengan sistem yang baik akan tercipta internal kontrol yang dapat mengurangi kesalahan-kesalahan dan mendukung kedisiplinan serta moral kerja karyawan

f. Sanksi Hukuman

Sanksi hukuman berperan penting dalam memelihara kedisiplinan karyawan. Dengan sanksi hukuman yang semakin berat, karyawan akan semakin takut melanggar peraturan-peraturan perusahaan, sikap, dan perilaku indisipliner karyawan akan berkurang. Sanksi hukuman harus ditetapkan berdasarkan pertimbangan logis, masuk akal dan diinformasikan secara jelas kepada semua karyawan. Sanksi hukuman seharusnya tidak terlalu ringan atau terlalu berat supaya hukuman itu tetap mendidik karyawan untuk mengubah perilakunya. g. Ketegasan

Pimpinan yang berani bertindak tegas menerapkan hukuman bagi karyawan yang indisipliner akan disegani dan diakui kepemimpinannya oleh bawahan. Sebaliknya apabila pimpinan kurang tegas atau tidak menghukum karyawan yang indisipliner, sulit baginya untuk memelihara kedisiplinan bawahannya, bahkan sikap indisipliner karyawan semakin banyak karena mereka beranggapan bahwa peraturan dan sanksi hukumannya tidak berlaku lagi.

h. Hubungan Kemanusiaan

Manajer harus berusaha mencipatakan suasana hubungan kemanusiaan yang serasi serta mengikat, vertikal maupun horizontal di antara semua karyawannya. Hal ini akan memotivasi kedisiplinan yang baik pada perusahaan.

Menurut Singodimejo dalam Sutrisno (2011:94) indikator disiplin kerja adalah sebagai berikut:

1. Taat terhadap aturan waktu Dilihat dari jam masuk kerja, jam pulang, dan jam istirahat yang tepat waktu sesuai dengan aturan yang berlaku di perusahaan.

2. Taat terhadap peraturan perusahaan Peraturan dasar tentang cara berpakaian, dan bertingkah laku dalam pekerjaan.

3. Taat terhadap aturan perilaku dalam pekerjaan Ditunjukan dengan cara-cara melakukan pekerjaan-pekerjaan sesuai dengan jabatan, tugas, dan tanggung jawab serta cara berhubungan dengan unit kerja lain.

4. Taat terhadap peraturan lainnya diperusahaan Aturan tentang apa yang boleh dan apa yang tidak boleh dilakukan oleh para pegawai dalam perusahaan

\section{Indikator Produktivitas Kerja}

Menurut Henry ( 2004: 612) faktor-faktor yang mempengaruhi produktivitas kerja meliputi kuantitas kerja, kualitas kerja dan ketepatan waktu.

1. Kuantitas Kerja

Menurut Wungu dan Brotoharsojo (2003:56) bahwa "Quantity (kuantitas) adalah segala bentuk satuan ukuran yang terkait dengan jumlah hasil kerja dan dinyatakan dalam ukuran angka atau yang dapat dipadankan dengan angka". Sedangkan 
menurut Wilson dan Heyyel (1987:101) mengatakan bahwa "Quantity of Work (kuantitas kerja) adalah jumlah kerja yang dilaksanakan oleh seseorang pegawai dalam suatu periode tertentu. Hal ini dapat dilihat dari hasil kerja pegawai dalam kerja penggunaan waktu tertentu dan kecepatan dalam menyelesaikan tugas dan tanggung jawabnya." Dengan demikian kuantitas kerja dapat dilihat dari jumlah kerja dan penggunaan waktu. Jumlah kerja adalah banyaknya tugas pekerjaanya, dapat dikerjakan. Penggunaan waktu adalah banyaknya waktu yang digunakan dalam menyelesaikan tugas dan pekerjaan.

2. Kualitas Kerja

Menurut Wungu dan Brotoharsojo (2003:57) bahwa "Quality (kualitas) adalah segala bentuk satuan ukuran yang terkait dengan mutu atau kualitas hasil kerja dan dinyatakan dalam ukuran angka atau yang dapat dipadankan dengan angka". Sedangkan menurut Wilson dan Heyel (1987:101) mengatakan bahwa "Quality of work (kualitas kerja) menunjukkan sejauh mana mutu seorang pegawai dalam melaksanakan tugas-tugasnya meliputi ketepatan, kelengkapan, dan kerapian".

Dari pendapat diatas, jelas bahwa kualitas kerja dapat diukur melalui ketepatan, kelengkapan, dan kerapian. Yang dimaksud ketepatan adalah ketepatan dalam melaksanakan tugas dan pekerjaan, artinya terdapat kesesuaian antara rencana kegiatan dengan sesaran atau tujuan yang telah ditetapkan. Yang dimaksud dengan kelengkapan adalah kelengkapan ketelitian dalam melaksanakan tugasnya. Yang dimaksud kerapian adalah kerapian dalam melaksanakan tugas dan pekerjaannya.

3. Ketepatan Waktu

Definisi ketepatan waktu (timeliness) menurut Chairil dan Ghozali (2001)dalam Ukago (2005) adalah "timeliness adalah suatu pemanfaatan informasi oleh pengambil keputusan sebelum informasi tersebut kehilangan kapasitas atas kemampuannya untuk mengambil keputusan" Ketepatan waktu bagi pemakai informasi sangat penting, informasi yang tepat waktu berarti jangan sampai informasi yang disampaikan sudah basi atau sudah menjadi rahasia umum. Definisi tepat waktu menurut Baridwan (1997) dalam Anastasia dan Mukhlisin (2003)“ informasi harus disampaikan sedini mungkin agar dapat digunakan sebagai dasar didalam pengambilan keputusan- keputusan ekonomi dan untuk menghindari tertundanya pengambilan keputusan tersebut".

\section{Hasil Penelitian Terdahulu Yang Relevan}

1. Penelitian yang dilakukan Muhammad Sukri (2014), dalam penelitiannya Muhammad Sukri (2014) menggunakan tipe penelitian kuantitatif dan teknik analisis data deskriptif, hasil penelitiannya menyatakan bahwa dari penelitian ini diperoleh kesimpulan bahwa pengaruh displin kerja terhadap produktivitas kerja tergolong "Cukup" yaitu sebesar 39,1\% Studi Pada Badan Pemberdayaan Perempuan, Perlindungan Anak dan Keluarga Berencana Kota Tanjung pinang.

2. Penelitian yang dilakukan Safitri Indriyani (2015), dalam penelitiannya Teknik analisis data yang digunakan adalah regresi berganda. Hasil penelitian pada taraf signifikansi $5 \%$ menunjukkan bahwa:

terdapat pengaruh positif dan signifikan pelatihan kerja terhadap produktivitas kerja karyawan pada PT. Paradise Island Furniture. Hal ini dibuktikan dengan koefisien beta $(\beta)$ sebesar $0,303(* * p<0.05$; $\mathrm{p}=0,000)$ dan kontribusi pengaruh pelatihan kerja terhadap produktivitas kerja karyawan pada PT. Paradise Island Furniture sebesar $(\Delta \mathrm{R} 2)$ 0,070; (2) terdapat pengaruh positif dan signifikan disiplin kerja terhadap produktivitas kerja karyawan pada PT. Paradise Island Furniture. Hal ini dibuktikan dengan koefisien beta $(\beta)$ sebesar $0,321(* * p<0.05$; $\mathrm{p}=0,000)$ dan kontribusi pengaruh disiplin kerja terhadap produktivitas kerja karyawan pada PT. Paradise Island Furniture sebesar $(\Delta R 2)$ 0,080; dan (3) terdapat pengaruh positif dan signifikan pelatihan kerja dan disiplin kerja terhadap produktivitas kerja karyawan pada PT. Paradise Island Furniture. Hal ini dibuktikan dengan hasil statistik uji regresi diperoleh pelatihan kerja dengan koefisien beta $(\beta)$ sebesar $0,263 \quad(* * \mathrm{p}<0.05$; $\mathrm{p}=0,000)$ dan disiplin kerja $(\beta) 0,284 \quad\left({ }^{*} \mathrm{p}<0.05\right.$; $\mathrm{p}=0,000$ ) berpengaruh positif dan signifikan terhadap produktivitas kerja karyawan. Kontribusi pengaruh pelatihan kerja dan disiplin kerja terhadap produktivitas kerja karyawan sebesar $(\Delta \mathrm{R} 2) 0,131$

3. Penelitian yang dilakukan Stief A. S. Tulenan. (2015) dalam penelitiannya, yang digunakan adalah penelitian kuantitatif, Teknik sampling yang 
digunakan adalah sample random sampling dengan rumus Slovin. Data diperoleh dari responden dengan menggunakan alat pengumpul data berupa kuesioner. Analisis data yang digunakan adalah analisis korelasi dan regresi sederhana, deskripsi statistik variabel, pengujian Validitas dan Reliabilitas, serta analisis grafik. Pengujian data menggunakan alat bantu program SPSS 20. Hasil penelitian dari total skor variabel menunjukkan bahwa disiplin kerja dan tingkat produktivitas kerja yang ada di Travello Hotel Manado masih tergolong rendah. Terdapat pengaruh yang positif dan signifikan antara disiplin kerja terhadap produktivitas kerja karyawan Travello Hotel Manado. Berdasarkan penelitian yang telah dilakukan diharapkan bagi perusahaan untuk memperhatikan disiplin kerja yang ada di perusahaan untuk mencapai tujuan yang diharapkan.

4. Penelitian yang dilakukan Feni Pertiwi (2017) Sampel yang diambil dalam penelitian ini menggunakan teknik sampling jenuh, yang merupakan suatu teknis sampling dimana mengambil semua jumlah populasi. Populasi sekaligus sampel tersebut adalah pegawai yang ada di Kantor Dinas Perindustrian Perdagangan Koperasi dan UMKM Provinsi Kalimantan Timur Provinsi Kalimantan Timur yang berjumlah 93 pegawai. Analisi data yang digunakan dalam penelitian ini adalah korelasi statistic parametris, yaitu koefisien korelasi product moment dan analisis regresi sederhana. Berdasarkan analisis data dan pengujian hipotesis diketahui bahwa kedua variabel yaitu disiplin kerja $(\mathrm{X})$ dan produktivitas kerja (Y) mempunyai hubungan yang positif, hal ini dibuktikan dengan $r=0,722$ dimana pedoman untuk memberikan interpretasi yang dikemukakan oleh Sugiyono berada pada interval 0,60-0,799 yang termasuk kategori kuat. Dilanjutkan dengan uji regresi didapat nilai $\mathrm{b}$ sebesar 0,81 . Maka apabila disiplin kerja meningkat produktivitas kerja pun meningkat sebesar 0,81 . Dari hasil penelitian yang telah dilakukan oleh penulis, disiplin kerja pegawai negeri sipil di Kantor Dinas Perindustrian Perdagangan Koperasi dan UMKM Provinsi Kalimantan Timur Provinsi Kalimantan Timur termasuk dalam kategori cukup tinggi dan perlu peningkatan. Oleh karena itu disiplin kerja harus terus dipertahankan dan ditingkatkan agar produktivitas kerja pegawai dapat dipertahankan dan dapat meningkat semakin menjadi lebih baik pula dari waktu ke waktu.

5. Penelitian yang dilakukan Nasrun Syahputra dalam hasil penelitian dan pembahasan maka dapat disimpulkan bahwa Variabel disiplin kerja (X) berpengaruh positif dan signifikan terhadap produktivitas kerja pegawai (Y) pada Dinas Pertambangan dan Energi Hal ini dapat diketahui melalui pengujian nilai thitung $(\mathrm{X})=$ yaitu $4.277>$ 2,00, sedangkan Identifikasi determinan (R2) nilai 0,25 artinya bahwa sebesar $11,7 \%$. produktivitas kerja pegawai (Y) pada Dinas Pertambangan Dan Energi dapat dijelaskan dengan menggunakan variabel disiplin kerja serta sisanya 88,3\% dipengaruhi oleh variabel lain yang tidak dimasukkan dalam penelitian ini

\section{Hipotesis}

Hipotesis merupakan dugaan tentang hubungan antara dua variable atau lebih yang dinyatakan berdasarkan pemikiran peneliti atau diturunkan dari teori yang ada ( Sugiyono 2012:261 ).

Hipotesis dalam penelitian ini ditampilkan hanya hipotesis nol yang dibagi dalam 3 bagian, yaitu :

1. $H_{0}$ : Disiplin kerja (X) pegawai di Badan Kesatuan Bangsa dan Politik Provinsi Kalimantan Selatan tersebar di semua kategori tingkatan disiplin kerja atau berdistribusi normal.

$H_{0}$ : Tidak terdapat hubungan disiplin kerja (X) dilihat dari karakteristik ( usia, jenis kelamin, tingkat pendidikan, dan masa kerja ).

2. $H_{0}$ : Produktivitas kerja $(\mathrm{Y})$ pegawai di Badan Kesatuan Bangsa dan Politik Provinsi Kalimantan Selatan tersebar di semua kategori tingkatan produktivitas kerja atau berdistribusi normal.

$H_{0}$ : Tidak terdapat hubungan produktivitas kerja (Y) dilihat dari karakteristik ( usia, jenis kelamin, tingkat pendidikan, dan masa kerja ).

3. $H_{0}$ : Tidak terdapat hubungan antara disiplin kerja (X) dengan Produktivitas kerja (Y) di Badan Kesatuan Bangsa dan Politik Provinsi Kalimantan Selatan. 


\section{METODE PENELITIAN}

\section{Pendekatan Penelitian}

Dalam penelitian ini, peneliti menggunakan pendekatan metode kuantitatif. Pendekatan metode kuantitatif merupakan metode penelitian yang berupa angka-angka dan analisis menggunakan statistik. (Sugiyono, 2016:7).

Dengan mengacu pada konsep yang digunakan, yaitu untuk mengetahui dan memahami disiplin produktivitas kerja pada Badan Kesatuan Bangsa dan Politik Provinsi Kalimantan Selatan.

\section{Jenis Penelitian}

Jenis penelitian yang digunakan adalah penelitian kuantitatif dengan pendekatan asosiatif. yaitu penelitian yang memiliki kejelasan unsur yang dirinci sejak awal, langkah penelitian yang sistematis, menggunakan sampel yang hasil penelitiannya diberlakukan untuk populasi, memiliki hipotesis jika perlu, dengan langkahlangkah penelitian dan hasil yang diharapkan, memerlukan pengumpulan data yang dapat mewakili, serta ada analisis data yang dilakukan setelah semua data terkumpul.

Sedangkan metode asosiatif menurut Sugiyono (2016:69) merupakan penelitian yang bertujuan untuk mengetahui hubungan dua variabel atau lebih.

\section{Populasi dan Sampel}

Populasi dalam penelitian ini adalah pegawai Badan Kesatuan Bangsa dan Politik Provinsi Kalimantan Selatan yang berjumlah 42 orang. Sampel yang digunakan dalam penelitian ini sebanyak 42 orang. Teknik pengambilan sampel menggunakan teknik non-probability sampling dengan jenis purposive sampling.

\section{Teknik Pengumpulan Data}

Teknik pengumpulan data yang digunakan dalam penelitian ini menggunakan dokumentasi dan kuesioner.

\section{Definisi Operasional Variabel}

Definisi operasional dimaksud untuk menjabarkan variabel-variabel yang timbul dalam suatu penelitian kedalam indikator-indikator yang lebih terperinci.

\section{Variabel Disiplin Kerja (X) Independen}

Disiplin kerja adalah suatu alat yang digunakan para manajer untuk berkomunikasi dengan karyawan agar mereka bersedia untuk mengubah suatu perilaku dan untuk meningkatkan kesadaran juga kesediaan seseorang agar menaati semua peraturan dan norma sosial yang berlaku di suatu perusahaan.

2. Variabel produktivitas Kerja (Y) Dependen

Produktivitas adalah suatu konsep yang bersifat universal yang bertujuan untuk menyediakan lebih banyak barang dan jasa yang akan digunakan oleh banyak manusia, dengan menggunakan sumbersumber riil yang semakin sedikit.

\section{Analisis Data}

\section{Analisis Uji Satu Variabel}

Analisis untuk uji satu variable seperti produktivitas kerja dan disiplin kerja menggunakan rumus chi square goodness of fit untuk melihat tersebarnya atau tidaknya variabel tersebut dalam kategori Sangat Baik, Baik, Cukup Baik, dan Kurang Baik. Sedangkan untuk melihat perbedaan karakteristik pegawai ( dalam hal ini usia, jenis kelamin, tingkat pendidikan, dan masa kerja ) yaitu dengan menggunakan statistic chi square test of independence. Perhitungan dilakukan dengan bantuan progam IBM SPSS Statistics 21.0 For Windows. Dasar pengambilan kesimpulan untuk menentukan hipotesis adalah:

Jika nilai Chi Square hitung $<$ Chi Square tabel maka $H_{0}$ diterima.

Jika nilai Chi Square hitung $>$ Chi Square tabel maka $H_{0}$ ditolak.

\section{Analisis Hubungan}

Sebelum dilakukan analisis uji hubungan akan dilakukan uji normalitas data dari hasl kuesioner dengan menggunakan statistic KolmogorovSmirnov. Untuk melihat hubungan antar variable dalam penelitian ini menggunakan teknik korelasi. Teknik korelasi yang digunakan adalah Korelasi Pearson Product Moment. Peritungan dilakukan dengan bantuan progam IBM SPSS Statistics 21.0 For Windows. Sebagai penafsiran terhadap koefisien korelasi yang ditemukan kuat atau lemah, maka dapat berpedoman pada ketentuan berikut: 
TABEL 1. PEDOMAN INTERPRESTASI KEERATAN HUBUNGAN

\begin{tabular}{|l|l|}
\hline \multicolumn{1}{|c|}{$\begin{array}{c}\text { Koefisien Korelasi } \\
\left(\mathrm{r}_{\mathrm{xy}}\right)\end{array}$} & \multicolumn{1}{c|}{ Keterangan } \\
\hline $0,800-1,000$ & Korelasi Sangat Tinggi \\
\hline $0,600-0,800$ & Korelasi Tinggi \\
\hline $0,400-0,600$ & Korelasi Cukup \\
\hline $0,200-0,400$ & Korelasi Rendah \\
\hline $0,000-0,200$ & Korelasi Sangat Rendah \\
\hline
\end{tabular}

ANALISIS HASIL PENELITIAN

\section{Analisis Uji Satu Variabel}

\section{Variabel Disiplin Kerja}

Gambaran disiplin kerja di Badan Kesatuan Bangsa dan Politik Provinsi Kalimantan Selatan dapat dilihat pada tabel berikut :

TABEL 2. GAMBARAN DISIPLIN KERJA

\begin{tabular}{|c|l|c|c|}
\hline NO & Kategori Penilaian & F & \% \\
\hline 1 & Cukup Baik & 15 & 35,7 \\
2 & Baik & 10 & 23,8 \\
3 & Sangat Baik & 17 & 40,5 \\
\hline \multicolumn{2}{|c|}{ Jumlah } & 42 & 100 \\
\hline
\end{tabular}

Sumber : Analisis Data Primer 2017

Hasil tersebut kemudian dianalisis dengan uji chi square goodness of fit, dimana diperoleh hasil chi square $\mathrm{X}^{2}$ hitung sebesar 1.857 nilai ini kemudian dibandingkan dengan nilai $\mathrm{X}^{2}$ tabel dengan taraf signifikan (5\%) pada df 2 yaitu 5,99. Karena $\mathrm{X}^{2}$ tabel 1.857 lebih kecil dari $\mathrm{X}^{2}$ tabel 5,99, dengan demikian $H_{0}$ diterima sehingga disiplin kerja $(\mathrm{X})$ pegawai Badan Kesatuan Bangsa dan Politik Provinsi Kalimantan Selatan tersebar di semua kategori tingkatan kategori disiplin karena disiplin kerja Badan Kesatuan Bangsa dan Politik Provinsi Kalimantan Selatan cenderung pada kategori sangat baik yaitu sebesar $66,7 \%$.

Untuk perbedaan disiplin kerja dilihat dari karakteristik jenis kelamin dapat dilihat pada tabel berikut:

TABEL 3. PERBEDAAN DISIPLIN KERJA DILIHAT DARI KARAKTERISTIK JENIS KELAMIN

\begin{tabular}{|c|c|c|c|c|c|}
\hline \multirow{2}{*}{ No. } & \multirow{2}{*}{ Jenis Kelamin } & \multicolumn{3}{|c|}{ Disiplin Pegawai } & \multirow{2}{*}{ Total } \\
\cline { 3 - 5 } & & $\mathrm{CB}$ & $\mathrm{B}$ & $\mathrm{SB}$ & \\
\hline 1. & Laki-Laki & 8 & 8 & 9 & 25 \\
2. & Perempuan & 7 & 2 & 8 & 17 \\
\hline \multicolumn{2}{|c|}{ Jumlah } & 15 & 10 & 17 & 42 \\
\hline
\end{tabular}

Sumber: Analisa Data Primer 2017
Hasil tersebut kemudian dianalisis dengan uji chi square goodness of fit, dimana diperoleh hasil chi square $\mathrm{X}^{2}$ hitung sebesar 2.285 dengan nilai probabilitas 0.319 , nilai ini kemudian dibandingkan dengan nilai $\mathrm{X}^{2}$ tabel dengan taraf signifikan (5\%) pada df 2 yaitu 5,99. Karena $X^{2}$ tabel 2.285 lebih kecil dari $\mathrm{X}^{2}$ tabel 5,99, dengan demikian $H_{0}$ diterima sehingga tidak terdapat perbedaan antara disiplin kerja (X) Badan Kesatuan Bangsa dan Politik Provinsi Kalimantan Selatan dilihat dari karakteristik jenis kelamin, karena disiplin kerja baik laki-laki maupun perempuan cenderung pada kategori sangat baik. Untuk perbedaan disiplin kerja dilihat dari karakteristik usia dapat dilihat pada tabel berikut:

TABEL 4. PERBEDAAN DISIPLIN KERJA DILIHAT DARI KARAKTERISTIK USIA

\begin{tabular}{|c|c|c|c|c|c|}
\hline \multirow{2}{*}{ No. } & \multirow{2}{*}{ Umur Pegawai } & \multicolumn{3}{|c|}{ Disiplin Pegawai } & \multirow{2}{*}{ Total } \\
\hline & & $\mathrm{CB}$ & $\mathrm{B}$ & SB & \\
\hline 1. & 23-30tahun & 3 & 1 & 3 & 7 \\
\hline 2. & 31-38 tahun & 4 & 1 & 3 & 8 \\
\hline 3. & 39-46 tahun & 3 & 3 & 1 & 7 \\
\hline 4. & 47-54 tahun & 1 & 2 & 4 & 7 \\
\hline 5. & 55-62 tahun & 4 & 3 & 6 & 13 \\
\hline & Jumlah & 15 & 10 & 17 & 42 \\
\hline
\end{tabular}

Sumber: Analisa Data Primer 2017

Hasil tersebut kemudian dianalisis dengan uji chi square goodness of fit, dimana diperoleh hasil chi square $\mathrm{X}^{2}$ hitung sebesar 5.276 dengan nilai probabilitas 0.728 , nilai ini kemudian dibandingkan dengan nilai $\mathrm{X}^{2}$ tabel dengan taraf signifikan (5\%) pada df 8 yaitu 15,51 . Karena $X^{2}$ tabel 5.276 lebih kecil dari $\mathrm{X}^{2}$ tabel 15,51, dengan demikian $H_{0}$ diterima sehingga tidak terdapat perbedaan antara disiplin kerja (X) Badan Kesatuan Bangsa dan Politik Provinsi Kalimantan Selatan dilihat dari karakteristik jenis kelamin, karena disiplin kerja pada masing-masing interval usia cenderung berada pada kategori sangat baik. Hal ini mencerminkan baik usia muda maupun tua tidak memiliki disiplin yang berbeda .

Untuk perbedaan disiplin kerja dilihat dari karakteristik tingkat pendidikan dapat dilihat pada tabel berikut: 
TABEL 5. PERBEDAAN DISIPLIN KERJA DILIHAT DARI KRAKTERISTIK TINGKAT PENDIDIKAN

\begin{tabular}{|c|c|c|c|c|c|}
\hline \multirow[t]{2}{*}{ No } & \multirow{2}{*}{$\begin{array}{c}\text { Tingkat } \\
\text { Pendidikan }\end{array}$} & \multicolumn{3}{|c|}{ Disiplin Pegawai } & \multirow{2}{*}{ Total } \\
\hline & & CB & B & SB & \\
\hline 1. & SD & - & - & 1 & 1 \\
\hline 2. & SLTP & - & - & 1 & 1 \\
\hline 3. & SLTA & 2 & 2 & 3 & 7 \\
\hline 4. & DIPLOMA & 2 & - & 2 & 4 \\
\hline 5. & S1 & 9 & 8 & 8 & 25 \\
\hline 6. & $\mathrm{~S} 2$ & 2 & - & 2 & 4 \\
\hline & Jumlah & 15 & 10 & 17 & 42 \\
\hline
\end{tabular}

Sumber: Analisa Data Primer 2017

Hasil tersebut kemudian dianalisis dengan uji chi square goodness of fit, dimana diperoleh hasil chi square $\mathrm{X}^{2}$ hitung sebesar 6.808 dengan nilai probabilitas 0.743 , nilai ini kemudian dibandingkan dengan nilai $\mathrm{X}^{2}$ tabel dengan taraf signifikan (5\%) pada df 10 yaitu 18,31. Karena $X^{2}$ tabel 6.808 lebih kecil dari $\mathrm{X}^{2}$ tabel 18,31, dengan demikian $H_{0}$ diterima sehingga tidak terdapat perbedaan antara disiplin kerja (X) Badan Kesatuan Bangsa dan Politik Provinsi Kalimantan Selatan dilihat dari karakteristik tingkat pendidikan, hal ini mencerminkan bahwa dengan tingkat pendidikan tinggi seseorang belum tentu memiliki disiplin kerja yang baik.

Untuk perbedaan disiplin kerja dilihat dari karakteristik masa kerja dapat dilihat pada tabel berikut:

TABEL 6. PERBEDAAN DISIPLIN KERJA DILIAT DARI KARAKTERISTIK MASA KERJA

\begin{tabular}{|c|c|c|c|c|c|}
\hline \multirow[t]{2}{*}{ No } & \multirow{2}{*}{ Masa Kerja } & \multicolumn{3}{|c|}{ Disiplin Pegawai } & \multirow{2}{*}{ Total } \\
\hline & & $\mathrm{CB}$ & $\mathrm{B}$ & SB & \\
\hline 1. & 2-9 tahun & 5 & 2 & 5 & 12 \\
\hline 2. & 10-17 tahun & 6 & 4 & 1 & 11 \\
\hline 3. & 18-25 tahun & 0 & 0 & 2 & 2 \\
\hline 4. & 26-33 tahun & 1 & 2 & 4 & 7 \\
\hline 5. & 34-41 tahun & 3 & 2 & 5 & 10 \\
\hline & Jumlah & 15 & 10 & 17 & 42 \\
\hline
\end{tabular}

Sumber: Analisa Data Primer 2017

Hasil tersebut kemudian dianalisis dengan uji chi square goodness of fit, dimana diperoleh hasil chi square $\mathrm{X}^{2}$ hitung sebesar 9.642 dengan nilai probabilitas 0.291 , nilai ini kemudian dibandingkan dengan nilai $\mathrm{X}^{2}$ tabel dengan taraf signifikan (5\%) pada df 8 yaitu 15,51 . Karena $X^{2}$ tabel 9.642 lebih kecil dari $\mathrm{X}^{2}$ tabel 15,51, dengan demikian $H_{0}$ diterima sehingga tidak terdapat perbedaan antara disiplin kerja (X) Badan Kesatuan Bangsa dan Politik Provinsi Kalimantan Selatan dilihat dari karakteristik jenis kelamin, karena disiplin kerja pada masing-masing interval cenderung pada kategori sangat baik dan hanya ada satu interval yang cenderung pada kategori baik. Hal ini mencerminkan bahwa dengan masa kerja yang lama belum tentu seorang pegawai memiliki disiplin kerja yang baik.

\section{Variabel Produktivitas Kerja}

Gambaran produktivitas kerja di Badan Kesatuan Bangsa dan Politik Provinsi Kalimantan Selatan dapat dilihat pada tabel berikut :

TABEL 7. GAMBARAN PRODUKTIVITAS KERJA

\begin{tabular}{|c|l|c|c|}
\hline NO & Kategori Penilaian & F & \% \\
\hline 1 & Cukup Baik & 7 & 16,7 \\
2 & Baik & 33 & 78,6 \\
3 & Sangat Baik & 2 & 4,7 \\
\hline \multicolumn{2}{|c|}{ Jumlah } & 42 & 100 \\
\hline
\end{tabular}

Sumber: Analisa Data Primer 2017

Hasil tersebut kemudian dianalisis dengan uji chi square goodness of fit, dimana diperoleh hasil chi square $\mathrm{X}^{2}$ hitung sebesar 39.571 nilai ini kemudian dibandingkan dengan nilai $\mathrm{X}^{2}$ tabel dengan taraf signifikan (5\%) pada df 2 yaitu 5,99. Karena $\mathrm{X}^{2}$ tabel 39.571 lebih kecil dari $\mathrm{X}^{2}$ tabel 5,99, dengan demikian $H_{0}$ diterima sehingga produktivitas kerja $(\mathrm{X})$ pegawai Badan Kesatuan Bangsa dan Politik Provinsi Kalimantan Selatan tersebar di semua kategori tingkatan kategori disiplin karena disiplin kerja Badan Kesatuan Bangsa dan Politik Provinsi Kalimantan Selatan cenderung pada kategori baik yaitu sebesar 78,6\%.

Untuk perbedaan produktivitas kerja dilihat dari karakteristik jenis kelamin dapat dilihat pada tabel berikut:

TABEL 8. PERBEDAAN PRODUKTIVITAS KERJA DILIHAT DARI KARAKTERISTIK JENIS KELAMIN

\begin{tabular}{|c|c|c|c|c|c|}
\hline \multirow{2}{*}{$\begin{array}{c}\text { No } \\
\text { * Jenis Kelamin }\end{array}$} & \multicolumn{3}{|c|}{ Produktivitas Kerja } & \multirow{2}{*}{ Total } \\
\cline { 3 - 5 } & & $\mathrm{CB}$ & $\mathrm{B}$ & $\mathrm{SB}$ & \\
\hline 1. & Laki-Laki & 4 & 19 & 2 & 25 \\
2. & Perempuan & 3 & 14 & 0 & 17 \\
\hline \multicolumn{2}{|c|}{ Jumlah } & 7 & 33 & 2 & 42 \\
\hline
\end{tabular}

Sumber: Analisa Data Primer 2017

Hasil tersebut kemudian dianalisis dengan uji chi square goodness of fit, dimana diperoleh hasil chi square $\mathrm{X}^{2}$ hitung sebesar 1.428 dengan nilai probabilitas 0.490 , nilai ini kemudian dibandingkan 
dengan nilai $\mathrm{X}^{2}$ tabel dengan taraf signifikan (5\%) pada df 2 yaitu 5,99. Karena $\mathrm{X}^{2}$ tabel 1.428 lebih kecil dari $\mathrm{X}^{2}$ tabel 5,99, dengan demikian $H_{0}$ diterima sehingga tidak terdapat perbedaan antara produktivitas kerja (X) Badan Kesatuan Bangsa dan Politik Provinsi Kalimantan Selatan dilihat dari karakteristik jenis kelamin, karena produktivitas kerja baik laki-laki maupun perempuan cenderung pada kategori baik .

Untuk perbedaan produktivitas kerja dilihat dari karakteristik usia dapat dilihat pada tabel berikut:

TABEL 9. PERBEDAAN PRODUKTIVITAS KERJA DILIHAT DARI KARAKTERISTIK USIA

\begin{tabular}{|c|l|l|l|l|l|}
\hline \multirow{2}{*}{ No. } & \multirow{2}{*}{ Umur Pegawai } & \multicolumn{3}{|c|}{ Produktivitas Kerja } & \multirow{2}{*}{ Total } \\
\cline { 3 - 5 } & & CB & B & SB & \\
\hline 1. & 23-30tahun & 2 & 5 & 0 & 7 \\
2. & 31-38 tahun & 2 & 6 & 0 & 8 \\
3. & 39-46 tahun & 2 & 5 & 0 & 7 \\
4. & 47-54 tahun & 1 & 6 & 0 & 7 \\
5. & 55-62 tahun & 0 & 11 & 2 & 13 \\
\hline & Jumlah & 7 & 33 & 2 & 42 \\
\hline
\end{tabular}

Sumber: Analisa Data Primer 2017

Hasil tersebut kemudian dianalisis dengan uji chi square goodness of fit, dimana diperoleh hasil chi square $\mathrm{X}^{2}$ hitung sebesar 8.386 dengan nilai probabilitas 0.397 , nilai ini kemudian dibandingkan dengan nilai $X^{2}$ tabel dengan taraf signifikan (5\%) pada df 8 yaitu 15,51 . Karena $\mathrm{X}^{2}$ tabel 8.386 lebih kecil dari $\mathrm{X}^{2}$ tabel 15,51, dengan demikian $H_{0}$ diterima sehingga tidak terdapat perbedaan antara produktivitas kerja (X) Badan Kesatuan Bangsa dan Politik Provinsi Kalimantan Selatan dilihat dari karakteristik jenis kelamin, karena produktivitas kerja pada masing-masing interval usia cenderung berada pada kategori sangat baik. Hal ini mencerminkan baik usia muda maupun tua tidak memiliki produktivitas yang berbeda .

Untuk perbedaan produktivitas kerja dilihat dari karakteristik tingkat pendidikan dapat dilihat pada tabel berikut:
TABEL 10. PERBEDAAN PRODUKTIVITAS KERJA DILIHAT DARI KARAKTERISTIK TINGKAT PENDIDIKAN

\begin{tabular}{|c|l|c|c|c|c|}
\hline \multirow{2}{*}{ No. } & Tingkat & \multicolumn{3}{|c|}{ Produktivitas Kerja } & \multirow{2}{*}{ Total } \\
\cline { 3 - 5 } & Pendidikan & CB & B & SB & \\
\hline 1. & SD & - & 1 & - & 1 \\
2. & SLTP & - & 1 & - & 1 \\
3. & SLTA & 1 & 6 & - & 7 \\
4. & DIPLOMA & 2 & 2 & - & 4 \\
5. & S1 & 4 & 19 & 2 & 25 \\
6. & S2 & - & 4 & - & 4 \\
\hline \multicolumn{2}{|l|}{ Jumlah } & 7 & 33 & 2 & 42 \\
\hline
\end{tabular}

Sumber: Analisa Data Primer 2017

Hasil tersebut kemudian dianalisis dengan uji chi square goodness of fit, dimana diperoleh hasil chi square $\mathrm{X}^{2}$ hitung sebesar 5.890 dengan nilai probabilitas 0.824 , nilai ini kemudian dibandingkan dengan nilai $X^{2}$ tabel dengan taraf signifikan (5\%) pada df 10 yaitu 18,31 . Karena $X^{2}$ tabel 5.890 lebih kecil dari $\mathrm{X}^{2}$ tabel 18,31, dengan demikian $H_{0}$ diterima sehingga tidak terdapat perbedaan antara disiplin kerja (X) Badan Kesatuan Bangsa dan Politik Provinsi Kalimantan Selatan dilihat dari karakteristik tingkat pendidikan, hal ini mencerminkan bahwa dengan tingkat pendidikan tinggi seseorang belum tentu memiliki produktivitas kerja yang baik .

Untuk perbedaan disiplin kerja dilihat dari karakteristik masa kerja dapat dilihat pada tabel berikut:

TABEL 11. PERBEDAAN PRODUKTIVITAS KERJA DILIHAT DARI KARAKTERISTIK MASA KERJA

\begin{tabular}{|c|c|l|l|l|l|}
\hline \multirow{2}{*}{ No. } & \multirow{2}{*}{ Masa Kerja } & \multicolumn{3}{|c|}{ Produktivitas } & \multirow{2}{*}{ Terja } \\
\cline { 3 - 4 } & & CB & B & SB & \\
\hline 1. & $2-9$ tahun & 4 & 8 & 0 & 12 \\
2. & $10-17$ tahun & 2 & 9 & 0 & 11 \\
3. & $18-25$ tahun & 1 & 1 & 0 & 2 \\
4. & $26-33$ tahun & 0 & 7 & 0 & 7 \\
5. & $34-41$ tahun & 0 & 8 & 2 & 10 \\
\hline \multicolumn{2}{|c|}{ Jumlah } & 7 & 33 & 2 & 42 \\
\hline
\end{tabular}

Sumber: Analisa Data Primer 2017

Hasil tersebut kemudian dianalisis dengan uji chi square goodness of fit, dimana diperoleh hasil chi square $\mathrm{X}^{2}$ hitung sebesar 13.433 dengan nilai probabilitas 0.098 , nilai ini kemudian dibandingkan dengan nilai $\mathrm{X}^{2}$ tabel dengan taraf signifikan (5\%) pada df 8 yaitu 15,51 . Karena $X^{2}$ tabel 13.433 lebih kecil dari $\mathrm{X}^{2}$ tabel 15,51, dengan demikian $H_{0}$ diterima sehingga tidak terdapat perbedaan antara disiplin kerja (X) Badan Kesatuan Bangsa dan 
Politik Provinsi Kalimantan Selatan dilihat dari karakteristik masa kerja, karena disiplin kerja pada masing-masing interval cenderung pada kategori baik dan hanya ada satu interval yang cenderung pada kategori sangat baik. Hal ini mencerminkan bahwa dengan masa kerja yang lama belum tentu seorang pegawai memiliki produktivitas kerja yang baik.

\section{Analisis Hubungan Disiplin Kerja dengan Produktivitas Kerja}

Berdasarkan hasil pengujian corelasi pearson product momen di peroleh hasil nilai koefisien korelasi sebesar 0.125 dibulatkan menjadi 0,12 nilai ini kemudian dibandingkan dengan pedoman interprestasi korelasi berikut ini :

TABEL 12. PEDOMAN INTERPRESTASI KEERATAN HUBUNGAN

\begin{tabular}{|l|l|}
\hline \multicolumn{1}{|c|}{$\begin{array}{c}\text { Koefisien Korelasi } \\
\left(\mathrm{r}_{\mathrm{xy}}\right)\end{array}$} & \multicolumn{1}{c|}{ Keterangan } \\
\hline $0,800-1,000$ & Korelasi Sangat Tinggi \\
\hline $0,600-0,800$ & Korelasi Tinggi \\
\hline $0,400-0,600$ & Korelasi Cukup \\
\hline $0,200-0,400$ & Korelasi Rendah \\
\hline $\mathbf{0 , 0 0 0}-\mathbf{0 , 2 0 0}$ & Korelasi Sangat Rendah \\
\hline
\end{tabular}

Sumber : (Budi Setiawan, 2015:64)

Mengacu pada tabel interprestasi koefisien korelasi dapat diketahui nilai koefisien korelasi antara variable disiplin kerja dengan produktivitas kerja adalah sebesar 0,12 berada pada interval 0,00 - 0,20 maka dapat diambil keputusan bahawa $\mathrm{H}_{\mathrm{o}}$ diterima sehingga tidak terdapat hubungan antara disiplin kerja dengan produktivitas kerja di Badan Kesatuan Bangsa dan Politik Provinsi Kalimantan Selatan.Namun hubungan disiplin kerja dengan produktivitas kerja sangat lemah.

\section{KESIMPULAN DAN SARAN \\ Kesimpulan}

Berdasarkan hasil penelitian yang dilakukan pada Badan Kesatuan Bangsa dan Politik Provinsi Kalimantan Selatan, maka kesimpulan yang dapat dikemukakan dalam penelitian ini adalah sebagai berikut :

1. Disiplin Kerja pada Badan Kesatuan Bangsa dan Politik Provinsi Kalimantan Selatan berdasarkan karakteristik usia, jenis kelamin, tingkat pendidikan dan masa kerja, hal ini ditunjukan bahwa disiplin pegawai lebih banyak pada kategori sangat baik yaitu 40,5\%, cukup baik $35,7 \%$, dan baik $23,9 \%$ dari 42 jumlah pegawai.

2. Produktivitas Kerja pada Badan Kesatuan Bangsa dan Politik Provinsi Kalimantan Selatan bahwa produktivitas kerja lebih banyak pada kategori baik yaitu $78,6 \%$, cukup baik $16,7 \%$, dan sangat baik $4,7 \%$ dari 42 jumlah pegawai.

3. Tidak Terdapat hubungan antara Disiplin Kerja dengan Produktivitas Kerja pada Badan Kesatuan Bangsa dan Politik Provinsi Kalimantan Selatan berdasarkan karakteristik usia, jenis kelamin, tingkat pendidikan dan masa kerja, dapat disimpulkan bahwa koefisien korelasi antara variabel disiplin pegawai (x) dengan kinerja pegawai (y) adalah sebesar $(r)=0,747 \quad$ dengan signifikansi 0,000 . Berdasarkan kriteria diatas dapat disimpulkan bahwa korelasi kedua variabel tersebut adalah tidak signifikan, sebab signifikansi yang menyertai lebih kecil dari 0,05 $(0,000<0,05)$. Dengan demikian korelasi antara variabel disiplin kerja dengan produktivitas kerja yang terjadi bersifat negatif, untuk itu apabila variabel bebas (independen) menurun, maka akan disertai oleh menurunnya variabel terikat (dependent), korelasi yang terjadi berada dalam kategori sangat rendah.

\section{Saran}

Berdasarkan pembahasan dan kesimpulan yang telah diuraikan, maka dapat diberikan beberap saran sebagai berikut :

1. Diperlukan adanya pelatihan maupun program pengembangan disiplin kerja agar produktivitas yang dicapai oleh pegawai pada Badan Kesatuan Bangsa dan Politik Provinsi Kalimantan Selatan dapat ditingkatkan lagi dalam segala aspek.

2. Diperlukan adanya peninjauan kembali terhadap disiplin produktivitas kerja pada Badan Kesatuan Bangsa dan Politik Provinsi Kalimantan Selatan karena masih terdapat beberapa kekurangan didalamnya.

3. Untuk mengukur disiplin kerja pada Badan Kesatuan Bangsa dan Politik Provinsi Kalimantan Selatan, sebaiknnya menggunakan pengukuran kinerja berbasis tim karena pada saat ini sebagian besar pekerjaan yang 
diberikan kepada pegawai adalah pekerjaan yang dilakukan secara tim, sehingga diharapkan produktivitas atau outputnya yang dicapai akan lebih baik.

\section{DAFTAR PUSTAKA}

Arsyad, Harun dan Bambang Hari Samasto. 2014. Modul Diklat Analisis Kepegawaian Disiplin PNS. PUSBINJAK BKN

Mulia, Elvie.2014.Office Power Office Politik. Jakarta: PT. Tigaraksa Tbk

Pertiwi, Feni.2017. Pengaruh Disiplin Kerja Terhadap Produktivitas Kerja Pegawai Negeri Sipil di Kantor Dinas Perindustrian Perdagangan Koperasi dan UMKM Provinsi Kalimantan Timur. Skripsi

Republik Indonesia. Undang-undang Dasar 1945

Republik Indonesia. Undang-undang Nomor 5 Tahun 2014 Tentang Aparatur Sipil Negara. Jakarta: Sekretariat Negara

Republik Indonesia. Peraturan Pemerintah Republik Indonesia Nomor 53 Tahun 2010 Tentang Disiplin Pegawai Negeri Sipil. Jakarta: Sekretariat Negara

Republik Indonesia. Peraturan Daerah Provinsi Kalimantan Selatan Nomor 1 Tahun 2012 Tentang Pembentukan Organisasi dan Tata Kerja Perangkat Daerah Provinsi Kalimantan Selatan. Banjarmasin: Sekretariat Daerah

Republik Indonesia. Peraturan Gubernur Kalimantan Selatan Nomor 045 Tahun 2013 Tentang Tugas Pokok, Fungsi dan Uraian Tugas Unsur-unsur Organisasi Badan Kesatuan Bangsa dan Politik Provinsi Kalimantan Selatan. Banjarmasin: Sekretariat Daerah

Rivai, Veithzal dan Ella Sagala. 2010. Manajemen Sumber Daya Manusia untuk Perusahaan: Dari Teori ke Praktik. Jakarta: PT Raja Grafindo Persada

Safitri, Indriyani.2015. Pengaruh Pelatihan Kerja dan Disiplin Kerja Terhadap Produktivitas Kerja Karyawan pada PT Paradise Island Furniture.Skripsi

Siagian, Sondang P. 2015. Manajemen Sumber Daya Manusia. Jakarta: Bumi Aksara

Septiasari, Devy. Mayang. 2017. Pengaruh Disiplin Kerja Terhadap Kinerja Pegawai Pada Dinas Perindustrian Perdagangan, Koperasi, dan Usaha Mikro Kecil dan Menengah Provinsi
Kalimantan Timur di Samarinda. Jurnal Administrasi Bisnis

Slovin, M. J. 1960. Sampling, Simon and Schuster Inc. New York.

Sugiyono. 2016. Metode Penelitian Kuantitatif Kualitatif dan $R \& D$. Bandung: $C V$. Alfabeta.

Sukri, Muhammad. 2014. Pengaruh Disiplin Kerja Terhadap Produktivitas Kerja Pegawai Negeri Sipil (Studi Pada Badan Pemberdayaan Perempuan, Perlindungan Anak dan Keluarga Berencana Tanjung Pinang). Skripsi

Syahputra, Nasrum. 2013.. Pengaruh Disiplin Kerja Terhadap Produktivitas Kerja Pegawai Dinas Pertambangan dan Energi Kabupaten Rokan Hulu. Skripsi

Tulenan, Stief A.S. 2015. Pengaruh Disiplin Kerja Terhadap Produktivitas Kerja Karyawan pada Hotel Travello Manado. Skripsi 